\title{
FiltraçÃo direta com PRÉ-FloculaçÃo e CoAgulaçÃo COM SULFATO DE ALUMÍNIO E HIDROXICLORETO DE ALUMÍNIO: ESTUDO COM ÁGUA DE MANANCIAL EUTROFIZADO
}

\author{
DIRECT FILTRATION WITH PRE-FLOCCULATION AND COAGULATION WITH \\ ALUMINIUM SULFATE AND POLY ALUMINIUM CHLORIDE: AN EUTROPHICATED \\ WATER SOURCE CASE STUDY
}

\section{RAMON LUCAS DALSASSO}

Engenheiro Sanitarista. Doutor em Engenharia Ambiental. Pesquisador do Departamento de Engenharia Sanitária e Ambiental da Universidade Federal de Santa Catarina - UFSC

MAURÍCIO LUIZ SENS

Engenheiro Sanitarista. Professor Titular do Departamento de Engenharia Sanitária e Ambiental da UFSC

\author{
Recebido: 02/06/05 Aceito 22/07/06
}

\begin{abstract}
RESUMO
Neste trabalho são apresentados dados de um estudo sobre modificaçōes em um sistema implantado de tratamento de água por filtração direta descendente, com o objetivo de melhorar o seu desempenho em função das características da água a ser tratada, caracterizada por baixa cor aparente e turbidez, porém com elevada concentração de fitoplâncton. Ensaios em jarteste precederam a realização de carreiras de filtração em sistema piloto, com ou sem pré-floculação em meio granular expandido. Foram testados sulfato de alumínio e hidróxicloreto de alumínio como coagulantes, e leitos filtrantes de antracito e areia ou apenas antracito. A adoção de um leito filtrante de maior granulometria, hidróxicloreto de alumínio e pré-floculação, reduziu o consumo de água de lavagem de $23,8 \%$ para $5,5 \%$, resultando água filtrada com melhor qualidade em termos de cor aparente, turbidez e alumínio residual.
\end{abstract}

PALAVRAS-CHAVE: Filtração direta, pré-floculação, floculador granular, tratamento de água.

\begin{abstract}
This paper presents the results of a case study on the modifications applied in a direct descending filtration water treatment system. The objective was to improve its performance according to the source water quality, characterized by low turbidity and apparent color levels, but high concentration of phytoplankton. Jar test procedures preceded the tests conducted in a small scale experiment, with or without a pre-flocculation step in expanded granular media. Aluminium sulfate and poly aluminium chloride were both tested as coagulant elements, and anthracite and sand or only anthracite were tested as the filtering media. The use of a large grain size filtering media with a poly aluminium chloride pre-flocculation step caused the washwater volume to reduce from $23.8 \%$ to $5.5 \%$. This resulted in a better water quality outcome measured in apparent color, turbidity and residual aluminium concentrations.
\end{abstract}

KEYWORDS: Direct filtration, pre-flocculation, granular flocculator, water treatment.

\section{INTRODUÇÃO}

A aplicação da filtração direta está fortemente condicionada à qualidade da água bruta, sendo relevantes os seguintes parâmetros: turbidez, cor verdadeira, sólidos em suspensão, densidade de algas e quantidade de coliformes (Di Bernardo et al, 2003). Os autores fazem menção também a importância da natureza e distribuição do tamanho das partículas. Caso predominem partículas com tamanho médio na faixa de 1 a $3 \mu \mathrm{m}$, é conveniente promover a floculação após a coagulação, para reduzir os custos operacionais da ETA e possibilitar a produção de água com melhor qualidade.

Arboleda (2000) ressalta que não há nada definitivo com relação à necessidade ou não de floculação prévia quando se aplica a filtração direta descendente. $\mathrm{O}$ autor relata experiências de outros autores, onde há casos de benefício na duração das carreiras de filtração pelo uso da préfloculação, mas há casos também em que foi observado o efeito contrário. A mesma observação foi feita com relação à qualidade da água filtrada, principalmente em relação ao tempo de floculação. Sendo assim, o autor recomenda o estudo de cada caso em particular.
Os mecanismos da filtração em meio granular resultam da ação conjunta de três fenômenos: transporte, aderência, e desprendimento das partículas em suspensão que se pretende remover. Em geral, o regime de escoamento na filtração é laminar, de modo que as partículas se movem ao longo de linhas de corrente. Para que sejam removidas é necessário que os mecanismos de transporte desviem suas trajetórias, conduzindo-as à superfície dos grãos (coletores) do meio filtrante, e as forças que tendem a mantê-la aderida ao coletor superem as que atuam do sentido de desprendê-las. 
Partículas com tamanho inferior a $1 \mu \mathrm{m}$ são eficientemente transportadas por difusão browniana até a superfície dos grãos que constituem o filtro, mantendo-se aderidas a ele se estiverem desestabilizadas. Entretanto partículas menores tendem a provocar maior perda de carga. Partículas maiores, da ordem de $10 \mu \mathrm{m}$ estão sujeitas ao transporte por ação hidrodinâmica quando sujeitas a gradientes de velocidade diferente de zero, aspecto relacionado as características do meio granular e a taxa de filtração.

Para tentar melhorar a eficiência do processo pode-se promover a floculação prévia e/ou aumentar a granulometria do meio filtrante. A Floculação prévia tem por objetivo aumentar o tamanho das partículas encaminhadas ao filtro. De acordo com Brandão et al (1996) a perda de carga desenvolvida por um filtro, para um mesmo volume de sólidos retidos, será tanto menor quanto maior for o tamanho das partículas que chegam à unidade, o que a princípio, permitiria adotar taxas de filtração mais elevadas.

A esse respeito De Pádua (2001) destaca que a qualidade da água produzida em unidades de filtração de alta taxa, não é afetada substancialmente quando se adotam taxas de até $600 \mathrm{~m}^{3} / \mathrm{m}^{2}$.d, desde que a água seja adequadamente pré-condicionada, contudo, valores elevados de taxa de filtração influenciam de modo expressivo a perda de carga.

O aumento da granulometria deve ser compensado pelo aumento da espessura da camada filtrante para garantir a mesma eficiência da filtração (Arboleda, 2000). A adoção de tal medida permitirá a penetração mais profunda do material floculado no meio filtrante. Sendo assim, os flocos deverão resistir às forças de cisalhamento para serem transportados ao longo dos caminhos tortuosos formados pelos espaços intergranulares.

A resistência e a densidade dos flocos podem ser influenciadas pelo tipo e dosagem de coagulante ou do auxiliar de coagulação utilizado no tratamento, assim como pelas condiçôes de coagulação e floculação.

Rissoli et al (2000) estudaram a pré-filtração em pedregulho como pré-tratamento à filtração rápida descendente, para tratar água de lago com elevada concentração de algas. Seus estudos indicaram a necessidade de material granular com tamanho efetivo de pelo menos 2,4 mm no filtro descendente, para a obtenção de carreiras com duração aceitável.

A estação de tratamento de água da lagoa do Peri foi projetada com a tecnologia da filtração direta descendente. Essa concepção mostrou-se compatível à qualidade da água do manancial citado, sobretudo em termos de cor verdadeira e turbidez, até hoje inferiores a $20 \mathrm{uH}$ e 10 UT respectivamente, em $100 \%$ do tempo.

O manancial caracteriza-se pela presença de fitoplâncton, com domínio de espécies filamentosas como a Cylindrospermopsis raciborskii e Pseudoanabaena sp (Laudares, 1999). Após um ano do início da operação da ETA, foi constatada a elevação da concentração de fitoplânctons. Os valores até então registrados da ordem de 10.000 indivíduos $/ \mathrm{mL}$ ou menos, deram lugar a sucessivas ocorrências de picos da ordem de 100.000 indivíduos $/ \mathrm{mL}$, atingindo até 250.000 indivíduos $/ \mathrm{mL}$. A mudança ocorrida na qualidade da água bruta trouxe problemas operacionais pela redução da duração das carreiras de filtração, e pela qualidade da água produzida. Para tentar manter a tecnologia de tratamento da ETA em questão, foi desenvolvido o presente trabalho, cujos objetivos são apresentados a seguir.

\section{OBJETIVOS}

Estudar medidas para adequação e otimização da ETA da lagoa do Peri, que utiliza a tecnologia da filtração direta, para tratamento de água com elevada concentração de fitoplâncton, destinada ao abastecimento público.

\section{METODOLOGIA}

As investigações experimentais foram realizadas em sistema piloto no Laboratório de Águas da Lagoa do Peri L.A.L.P. (convênio UFSC/CASAN - Companhia Catarinense de Águas e Saneamento), situado na Estação de Tratamento de Água da Lagoa do Peri, em Florianópolis SC. A ETA citada é do tipo Filtração Direta Descendente, com meio filtrante de dupla camada (antracito e areia) e utiliza sulfato de alumínio como coagulante.

O sistema piloto utilizado nos ensaios está representado pela Figura 1. A água bruta proveniente da lagoa do Peri, alimenta constantemente o reservatório inferior, de onde é bombeada para uma câ- mara de nível constante dotada de orifício calibrado. A vazão excedente retorna para o tanque de água bruta. A câmara de mistura rápida é alimentada com vazão constante e recebe os produtos químicos através de bombas dosadoras de diafragma.

Inicialmente foram realizados ensaios em jarteste para definir as condiçôes de mistura rápida (gradiente de velocidade e tempo) e coagulação ( $\mathrm{pH}$ e dosagem de coagulante). Os ensaios foram feitos com um equipamento modelo LDB310 da Nova Ética com as seguintes características: 6 cubas de $2 \mathrm{~L}$; gradiente de velocidade variável de 10 a $2000 \mathrm{~s}^{-1}$ (20 a $\left.800 \mathrm{rpm}\right)$; controle de rotação por tacógrafo digital e extração simultânea de amostras. A filtração das amostras foi feita em Filtros de Laboratório de Areia (FLAs) acoplados ao aparelho de jarteste, com as seguintes características: meio filtrante com $15 \mathrm{~cm}$ de areia (grãos de $0,42 \mathrm{a} 0,84 \mathrm{~mm}$ e tamanho efetivo $0,5 \mathrm{~mm}$ ); filtração com taxa entre 80 a $100 \mathrm{~m}^{3} / \mathrm{m}^{2} . \mathrm{d}$ com carga hidráulica constante.

Como coagulantes foram utilizadas soluçôes a $1 \%$ preparadas com água filtrada, dos produtos comerciais: Sulfato de Alumínio (SA), com 14,4\% de $\mathrm{Al}_{2} \mathrm{O}_{3}$, e Hidroxicloreto de Alumínio (PANFLOC AB34 da Panamericana S.A), com 10,5\% de $\mathrm{Al}_{2} \mathrm{O} 3$ e $67,47 \%$ de basicidade. Para ajustes do $\mathrm{pH}$ de coagulação utilizou-se solução de cal hidratada comercial a $0,5 \%$ ou solução de ácido sulfúrico PA $0,05 \mathrm{~N}$, ambas preparadas com água filtrada. Os demais produtos químicos utilizados nas análises de qualidade da água foram PA.

A mistura rápida em sistema piloto foi feita por agitador mecânico com rotação regulável. A partir da câmara de mistura rápida, cujo volume pode ser regulado, o sistema piloto é alimentado por gravidade, podendo a água coagulada passar ou não pelo floculador.

A floculação foi realizada em meio granular expandido. O floculador foi construído com tubo de acrílico transparente, com diâmetro interno de $115 \mathrm{~mm}$ e altura total de $3,2 \mathrm{~m}$. O material granular tem as seguintes características: massa específica $=$ $1,055 \mathrm{~g} / \mathrm{cm}^{3}$; diâmetro equivalente $=$ $3,3 \mathrm{~mm}$; coeficiente de esfericidade $=$ 0,86 ; porosidade $=39 \%$; base quími$\mathrm{ca}=$ PS (poliestireno); altura de leito antes da expansão $=1,61 \mathrm{~m}$. As características do floculador e condições operacionais como: gradiente de velo- 
cidade médio e tempo de floculação, foram definidas com base em estudos prévios com água do mesmo manancial (Dalsasso, 2003).

$\mathrm{Na}$ filtração foi reproduzida a técnica adotada pela ETA em foco, ou seja, filtração direta descendente. O filtro construído em chapas de aço inoxidável, com altura total de 4,2 $\mathrm{m}$, seção interna útil de $19,5 \times 19,5 \mathrm{~cm}$, possui visores laterais para observar a expansão do leito durante a lavagem. A operação foi com taxa constante de $200 \mathrm{~m}^{3} / \mathrm{m}^{2}$.d e carga hidráulica variável. As características dos leitos filtrantes avaliados estão na Tabela 1.

As carreiras foram encerradas quando a perda de carga total no meio granular, medida por piezômetros, atingiu $1,76 \mathrm{~m}$ ou por deterioração progressiva da qualidade da água filtrada.

Para cada ensaio foi coletado uma amostra composta de água filtrada para análise do alumínio residual. As técnicas analíticas e os equipamentos utilizados nas análises estão indicados no Tabela 2 .

A lavagem do filtro foi feita com ar e água filtrada bombeada, com dois ciclos: $2 \mathrm{x}$ (injeção de ar por $5 \mathrm{~min}+$ injeção de água filtrada por $5 \mathrm{~min}$ ). A injeção de água para lavagem, com velocidade ascensional de $1 \mathrm{~m} / \mathrm{min}$, foi controlada por medidor eletrônico de vazão. A injeção de ar, na razão de $20 \mathrm{~L} / \mathrm{s} . \mathrm{m}^{2}$ ( $2736 \mathrm{~L} / \mathrm{h}$ ), foi controlada pela regulagem da pressão de alimentação, fixada em $1 \mathrm{~atm}$, previamente aferida com rotâmetros.

O tempo total de lavagem dos filtros com água foi $10 \mathrm{~min}$ para todos os ensaios. Nessas circunstâncias, em função das dimensões do filtro e da velocidade ascensional anteriormente indicada, o volume de água gasto em cada lavagem foi $\mathrm{Val}=360 \mathrm{~L}$. Considerando também a vazão de alimentação do filtro $\mathrm{Q}=317 \mathrm{~L} / \mathrm{h}$, os cálculos percentuais do consumo de água de lavagem e produção efetiva foram feitos como segue:

$\mathrm{Val} \%=(\mathrm{Val} / \mathrm{Q} \cdot \mathrm{dc}) \cdot 100=$ consumo de água de lavagem (\%), onde $\mathrm{dc}=$ duração da carreira (h). Pe\% = $100-\mathrm{Val} \%=$ produção efetiva do filtro (\%).

Por limitações do sistema piloto, não foi possível realizar simultaneamente ensaios com e sem pré-floculação. Tal procedimento foi permitido, porque as variações diárias de qualidade da água bruta são pequenas, conforme análise estatística apresentada em resultados e discussões. Ressalte-se também a possibilidade do efetivo controle da vazão de alimentação do sistema piloto, dosagem de produtos químicos e condiçôes de coagulação.

Os ensaios foram feitos em dias consecutivos e de forma alternada, com e sem pré-floculação. Foram feitos três séries de ensaios totalizando 20 ensaios conforme segue:

1. Série A: meio filtrante L2 e sulfato de alumínio como coagulante - 8 ensaios (4 com e 4 sem pré-floculação);

2. Série B: meio filtrante L1 e sulfato de alumínio como coagulante - 6 ensaios (3 com e 3 sem pré-floculação);

3. Série C: meio filtrante $\mathrm{L} 1 \mathrm{e}$ hidróxicloreto de alumínio como coa- gulante -6 ensaios (3 com e 3 sem pré-floculação).

Inicialmente foram realizados os ensaios da série A. Em seguida o meio filtrante foi substituído para a realização dos demais ensaios. Alguns ensaios foram desconsiderados e refeitos em função da não obtenção do mesmo padrão de qualidade da água filtrada. Após a troca do meio filtrante de L2 para L1, constatou-se que nos primeiros ensaios, e de forma mais acentuada nas primeiras cinco horas de cada ensaio, o pH da água filtrada resultou inferior ao da coagulada. Em função desse aspecto que afetava a qualidade da água produzida pelo filtro, oito ensaios foram desconsiderados e refeitos na série B.

\section{RESULTADOS E DISCUSSÕES}

As variaçōes na qualidade da água bruta durante período de estudo são mostradas na Tabela 3. As variações com influência mais acentuada sobre a filtração direta são relacionadas a matéria em suspensão, ou seja, fitoplâncton e turbidez. O fitoplâncton na lagoa do Peri tem influência sazonal, com forte presença no verão.

A turbidez em parte é devida ao fitoplâncton, mas também varia em função dos ventos, principalmente do quadrante norte, que provocam o embate das águas nas margens e o revolvimento do material sedimentado no fundo da lagoa, junto a captação que alimenta a ETA e o sistema piloto.

A cor aparente e o COT são influenciados pelo fitoplâncton e pela

Tabela I - Composição dos meios filtrantes utilizados no filtro piloto

\begin{tabular}{|c|c|c|c|}
\hline Características & Meio L1 & \multicolumn{2}{|c|}{ *Meio L2 } \\
\hline Material & Antracito & Antracito & Areia \\
\hline Espessura da camada & $143 \mathrm{~cm}$ & $90 \mathrm{~cm}$ & $30 \mathrm{~cm}$ \\
\hline Tamanho efetivo dos grãos & $2,5 \mathrm{~mm}$ & $1,1 \mathrm{~mm}$ & $0,50 \mathrm{~mm}$ \\
\hline Coeficiente de desuniformidade (CD) & 1,1 & 1,1 & $<2$ \\
\hline \multicolumn{4}{|c|}{ Características da camada suporte com $35 \mathrm{~cm}$ de espessura utilizada em todos os casos } \\
\hline Subcamadas & Diâmetro $(\mathrm{mm})$ & \multicolumn{2}{|c|}{ Espessura $(\mathrm{cm})$} \\
\hline Topo & 19,0 a 12,7 & \multicolumn{2}{|c|}{5} \\
\hline $6^{a}$ camada & 12,7 a 6,4 & \multicolumn{2}{|c|}{5} \\
\hline $5^{\mathrm{a}}$ camada & 6,4 a 3,2 & \multicolumn{2}{|c|}{5} \\
\hline $4^{\mathrm{a}}$ camada & 3,2 a 1,6 & \multicolumn{2}{|c|}{5} \\
\hline $3^{\mathrm{a}}$ camada & 3,2 a 6,4 & \multicolumn{2}{|c|}{5} \\
\hline $2^{\mathrm{a}}$ camada & 6,4 a 12,7 & \multicolumn{2}{|c|}{5} \\
\hline Base & 12,7 a 19,0 & \multicolumn{2}{|c|}{5} \\
\hline
\end{tabular}

* existente na ETA da lagoa do Peri 


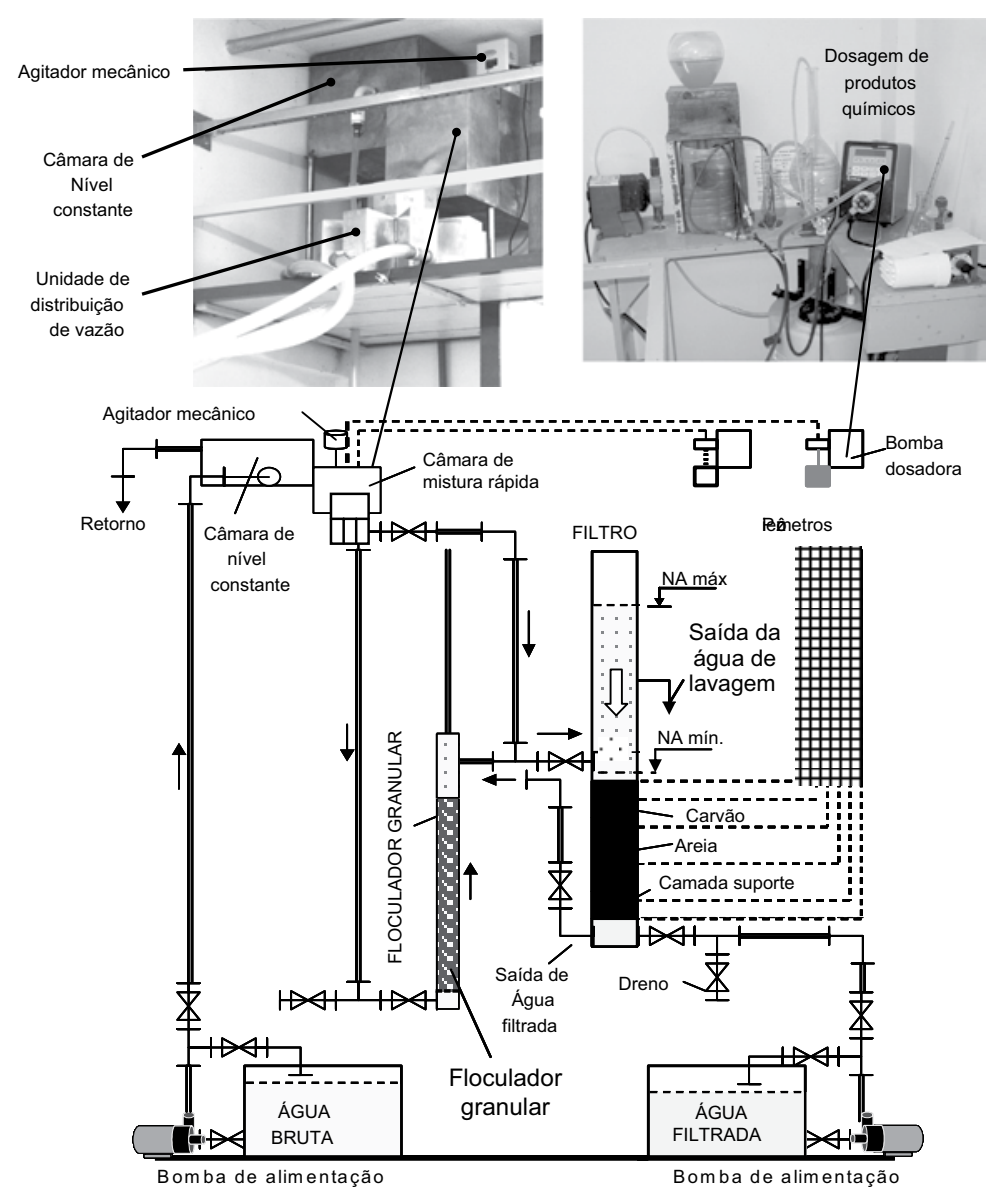

Figura I - Esquema geral do sistema piloto de floculação/filtração direta

Tabela 2 - Parâmetros de controle de qualidade da água, métodos analíticos e freqüência das análises

\begin{tabular}{ccc}
\hline Parâmetro & Método analítico/Equipamento associado & ${ }^{1}$ Frequência/2Tipo de água \\
\hline Alcalinidade total & Volumétrico/Titulador digital HACH & $\mathrm{S} / \mathrm{B}$ \\
Alumínio & Kit HACH $/{ }^{* *}$ Espectrofotômetro & $\mathrm{D} / \mathrm{F}$ \\
Clorofila a & NUSCH - extração com etanol/*Espectrofotômetro & $\mathrm{S} / \mathrm{B}$ \\
Cor aparente & APHA Platinum-Cobalt $-\mathrm{S} . \mathrm{M} /{ }^{* *}$ Espectrofotômetro, \\
$\lambda=455 \mathrm{~nm}$ & $\mathrm{D} / \mathrm{B}-\mathrm{H} / \mathrm{F}$ \\
Cor verdadeira & Idem ao da cor aparente, com filtragem em membrana & \\
& $0,45 \mu \mathrm{m}$ & $\mathrm{S} / \mathrm{B}$ \\
${ }^{* * *}$ COT & Kit HACH $/{ }^{* *}$ Espectrofotômetro & \\
Condutividade & Condutivímetro HACH & $\mathrm{S} / \mathrm{B}$ \\
Cloretos & Volumétrico/Titulador digital c/nitrato de prata & $\mathrm{D} / \mathrm{B}$ \\
Dureza total & Volumétrico/ Titulador digital c/ EDTA & $\mathrm{S} / \mathrm{B}$ \\
Fitoplâncton & Contagem em câmara de SR com microscópio invertido $(\mathrm{S})$ & $\mathrm{S} / \mathrm{B}$ \\
Nitrato & Kit HACH $/ * *$ Espectrofotômetro & $\mathrm{S} / \mathrm{B}$ \\
Nitrogênio amoniacal & Kit HACH $/ * *$ Espectrofotômetro & $\mathrm{S} / \mathrm{B}$ \\
Oxigênio dissolvido & Kit HACH $/ * *$ Espectrofotômetro & $\mathrm{S} / \mathrm{B}$ \\
PH & pHmetro digital HACH SensIon & $\mathrm{S} / \mathrm{B}$ \\
Temperatura & Termômetro de mercúrio & $\mathrm{D} / \mathrm{B}-\mathrm{H} / \mathrm{F}, \mathrm{C}$ \\
Turbidez & Turbidímetro portátil HACH DR 2100P & $\mathrm{D} / \mathrm{B}-\mathrm{H} / \mathrm{F}, \mathrm{C}$ \\
\hline
\end{tabular}

*HACH DR 4000, **HACH DR 2010. ' ${ }^{*}$ Frequência: H=horária, $\mathrm{D}=$ diária, $S=$ semanal. ${ }^{2}$ Tipo de água: $\mathrm{B}=$ bruta, $\mathrm{C}=$ coagulada, Floc=floculada, $\mathrm{F}=$ filtrada. ${ }^{* * *}$ Método baseado na oxidação do carbono da amostra pelo persulfato. As amostras não são filtradas em membrana $0,45 \mu \mathrm{m}$. 
matéria vegetal decomposta que integra o solo do fundo da lagoa. Apesar de ampla, as variações de $\mathrm{pH}$ ocorreram na realização de apenas dois ensaios consecutivos. Na maior parte do tempo o $\mathrm{pH}$ esteve próximo da neutralidade.

$\mathrm{O}$ manancial em questão vem sendo estudado nos últimos três anos, e as variaçôes sofridas na qualidade de suas águas não difere muito da apresentada, exceto pela ocorrência de picos acentuados de fitoplâncton da ordem de 1,5x105 indivíduos/mL. Sabe-se que as concentraçôes de fitoplâncton encontradas são proibitivas para o emprego da filtração direta, porém cabe lembrar, que trata-se de uma ETA que passou apresentar problemas devido a presença desses organismos, um ano depois do início de operação. Esse trabalho é parte de um estudo maior, de alternativas para solucionar o problema sem modificar a tecnologia de tratamento.

Em data posterior aos estudos apresentados foi avaliado a distribuição do tamanho de partículas em um conjunto de amostras daquele manancial, que pode ser usado como referência para explicar os efeitos positivos obtidos pela pré-floculação. A Figura 2 mostra esses resultados, onde observase o predomínio de partículas com tamanhos $\leq 2 \mu \mathrm{m}$.

Os ensaios em jarteste mostraram variaçõoes nas condições de coagulação em função das características da água e do tipo de coagulante utilizado. Em termos de mistura rápida, independentemente da qualidade da água bruta e do coagulante utilizado, resultou: Gradiente de velocidade $\mathrm{G}=1200 \mathrm{~s}^{-1} \mathrm{e}$ tempo de mistura rápida $\mathrm{T}=30 \mathrm{~s}$.

Em termos de coagulação os parâmetros foram os seguintes: coagulação com sulfato de alumínio - SA (ensaios da série $\mathrm{A}) \Rightarrow$ dosagem $=1,22 \mathrm{a}$ $1,37 \mathrm{mg} / \mathrm{L} \mathrm{Al}{ }^{3+}, \mathrm{pH}$ de coagulação $=5,6$ a 5,8, turbidez da água filtra$\mathrm{da}=0,5 \mathrm{uT} ; \quad \mathrm{SA}$ (ensaios da série $\mathrm{B}) \Rightarrow$ dosagem $=1,67$ a 2,2 mg/L Al ${ }^{3+}$, $\mathrm{pH}$ de coagulação $=5,6$ a 5,8, turbidez da água filtrada $=0,5 \mathrm{uT}$; coagulação com hidróxicloreto de alumínio - PAC (ensaios da série $\mathrm{C}) \Rightarrow$ dosagem $=$ 1,0 a $1,1 \mathrm{mg} / \mathrm{L} \mathrm{Al}^{3+}, \mathrm{pH}$ de coagulação 5,5 a 6,5, turbidez da água filtra$\mathrm{da}=0,3 \mathrm{uT}$.

A Tabela 4 mostra os principais resultados obtidos nos ensaios realizados e considerados, em termos de qualidade da água bruta, condiçôes de coagulação e qualidade da água filtrada. As condiçōes de floculação foram: gradiente de velocidade médio $=55 \mathrm{~s}^{-1}$ (53 a 56); tempo médio de floculação $=2,85 \mathrm{~min}(2,8 \mathrm{a}$ 2,9); Velocidade ascensional $=731 \mathrm{~m} / \mathrm{d}$; Expansão média do leito $=52 \%(50 \mathrm{a}$ 53); GT médio = 9405 (9275 a 9576).

A Figura 3 mostra os valores médios de qualidade da água filtrada e duração das carreiras por série de ensaios realizados. Observa-se que nos ensaios da série $\mathrm{A}$ as carreiras tiveram duração média de 5 horas, com ou sem pré-floculação. Nos ensaios da série $\mathrm{B}$ a duração média foi da ordem de 13,4 horas, com ou sem pré-floculação, um aumento médio de $168 \%$ em relação aos ensaios da série $\mathrm{A}$.

Esse aumento foi devido a mudança da granulometria, cujo tamanho efetivo aumentou de $1,1 \mathrm{~mm}$ para $2,5 \mathrm{~mm}$, e na altura do meio filtrante, que passou de $0,9 \mathrm{~m}$ para $1,43 \mathrm{~m}$. Nas duas séries de ensaios em questão, o coagulante foi o sulfato de alumínio. $\mathrm{Na}$ série $\mathrm{A}$ a dosagem variou de 1,21 a $1,37 \mathrm{mg} / \mathrm{L}$ de $\mathrm{Al}^{3+}$, enquanto na série $\mathrm{B}$ a dosagem variou de 1,7 a 2,2 mg/L de $\mathrm{Al}^{3+}$. A qualidade da água filtrada na série $B$ foi ligeiramente superior em termos de cor aparente e turbidez, provavelmente devido a dosagem mais elevada de coagulante.

Nos ensaios da série C houve redução de $7,8 \%$ na duração das carreiras sem pré-floculação, em relação aos ensaios da série B, embora a dosagem de alumínio no primeiro caso tenha sido menor. Observa-se também através da Tabela 4 que nos ensaios sem pré-floculação da série $\mathrm{C}$, os valores de turbidez foram menores que na série $\mathrm{B}$, caracterizando melhor desempenho do PAC nesse aspecto e justificando a diferença na duração das carreiras.

Comparando apenas os ensaios da série C, a pré-floculação aumentou a duração das carreiras em 68\%. Considerando todas as séries de ensaios, a mudança na granulometria aumentou mais a duração das carreiras do que a pré-floculação. O aumento acumulado devido a mudança de granulometria, mudança de coagulante e pré-floculação, foi da ordem de 334\%.

Considerando que a ETA da lagoa do Peri possui 5 filtros, que o sistema de lavagem é 4 lavam 1, que o tempo total de lavagem de um filtro incluindo todas a manobras de injeção de ar e água é da ordem de $30 \mathrm{~min}$, entre o final de uma lavação de um filtro e o início da lavação do próximo, decorrem 3,84 h. Embora o aumento na duração das carreiras para $21,7 \mathrm{~h}$ conseguido com as alteraçôes citadas ainda seja baixo, do ponto de vista operacional permite manter a atual tecnologia de tratamento.

Os efeitos da pré-floculação nessa particular situação foram devidos a mudança do coagulante. De acordo com Di Bernardo et al (2003), alguns estudos ressaltam o melhor desempenho do PAC em relação ao SA na floculação, por apresentar maior estabilidade das espécies hidrolisadas, aspecto que favorece a agregação das partículas em menor tempo, e possibilita aplicar menores dosagens do coagulante para obter a mesma qualidade de água, quando comparado ao sulfato de alumínio. Os autores apresentam resultados de jarteste em que houve redução significativa na turbidez da água filtrada utilizando PAC, quando a basicidade do produto comercial passou de $8 \%$ para $18 \%$.

No presente estudo foi utilizado PAC com basicidade de 67,47\%. Uma das características do produto em foco, é a expressiva concentração de íons hidroxilas, que a partir de ligações de coordenação com átomos de alumínio, formam compostos polinucleares no interior das moléculas de coagulantes pré-polimerizados, propiciando menor redução do $\mathrm{pH}$ do meio, quando comparado aos tradicionais coagulantes inorgânicos. Esse aspecto é particularmente favorável para águas com baixa alcalinidade como as da lagoa do Peri.

Observou-se também que a faixa do $\mathrm{pH}$ de coagulação é mais ampla com a utilização do hidróxicloreto de alumínio do que com a utilização do sulfato de alumínio, aspecto que contribuiu para obtenção de água filtrada com melhores características, tanto em jarteste como em sistema piloto, quando da utilização daquele primeiro coagulante. Esse aspecto é muito importante para o controle da coagulação/floculação, sobretudo se a tecnologia de tratamento for a filtração direta, onde qualquer distúrbio nas etapas em questão pode resultar em queda na qualidade da água filtrada, seja em termos de cor e turbidez, como em termos de alumínio residual.

A Figura 4 ilustra a participação do meio filtrante na retenção de impurezas para três ensaios. $\mathrm{Na}$ figura citada o gráfico ( a ) representa um ensaio da série A sem pré-floculação. 
Tabela 3 - Características das águas da lagoa do Peri, janeiro-abril/2004

\begin{tabular}{cccc}
\hline Parâmetros & Variação & Parâmetros & Variação \\
\hline Alcalinidade $\left(\mathrm{mg} / \mathrm{L} \mathrm{CaCO}_{3}\right)$ & 6,5 a 13 & Dureza total $\left(\mathrm{mg} / \mathrm{L} \mathrm{CaCO}_{3}\right)$ & 6,5 a 13,6 \\
Clorofila a $(\mu \mathrm{g} / \mathrm{L})$ & 4,6 a 34,7 & Nitrogênio $\left(\mathrm{mg} / \mathrm{L} \mathrm{NH}_{4}\right)$ & 0,02 a 0,16 \\
Fitoplâncton $($ ind $/ \mathrm{mL})$ & $1,3 \times 10^{4}$ a $9,95 \times 10^{4}$ & Nitrato $\left(\mathrm{mg} / \mathrm{L} \mathrm{NO}_{3}^{-}\right)$ & 0,017 a 0,8 \\
Cor aparente $(\mathrm{uH})$ & 43 a 97 & Oxigênio dissolvido $(\mathrm{mg} / \mathrm{L})$ & 6,8 a 9,8 \\
Cor verdadeira $(\mathrm{uH})$ & 5 a 10 & pH & 6 a 9 \\
COT $(\mathrm{mg} / \mathrm{L})$ & 4,6 a 7,5 & Temperatura $\left({ }^{\circ} \mathrm{C}\right)$ & 22 a 31 \\
Condutividade $(\mu S / \mathrm{cm})$ & 53 a 80 & Turbidez $(\mathrm{uT})$ & 3 a 8,5 \\
Cloretos $\left(\mathrm{mg} / \mathrm{L} \mathrm{Cl}^{-}\right)$ & 11,4 a 22 & & \\
\hline
\end{tabular}

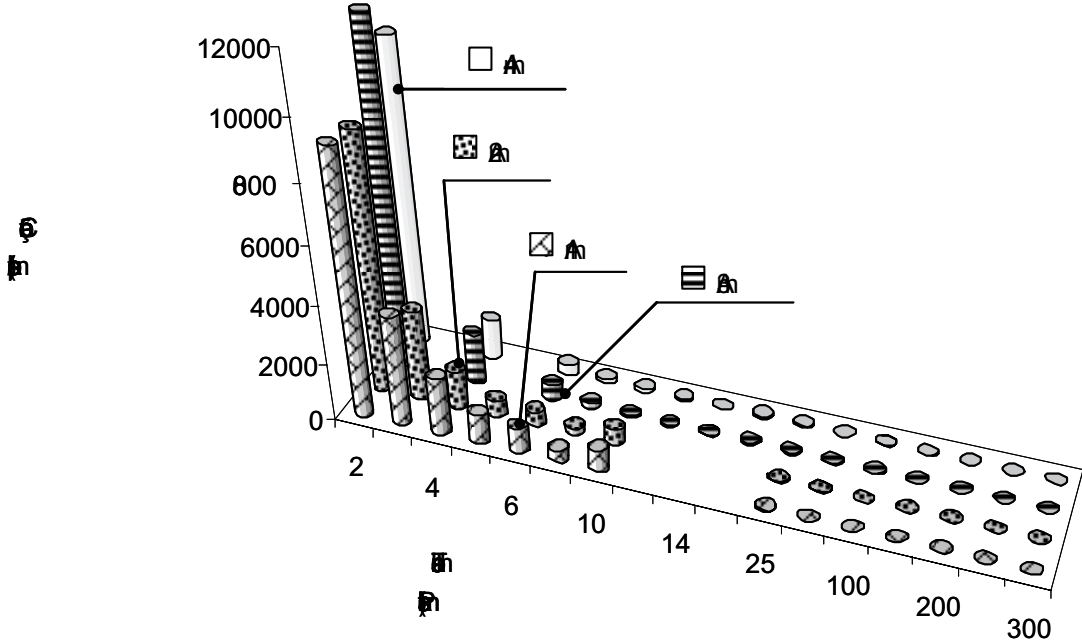

Figura 2 - Distribuição de partículas em amostras de água da lagoa do Peri, Junho2004

Nesse caso a retenção de impurezas ocorreu praticamente nos primeiros $30 \mathrm{~cm}$, atingindo seu limite próximo de $50 \mathrm{~cm}$. Esse comportamento ocorreu nos demais ensaios dessa série, com ou sem pré-floculação, resultando carreiras de curta duração.

Os gráficos ( b ) e ( c ) ressaltam a diferença da participação do meio filtrante em função da pré-floculação, do antracito com granulometria maior e do uso do PAC como coagulante. No caso ( b ) a participação do leito atingiu cerca de $1 \mathrm{~m}$, e no caso ( c ), com pré-floculação, atingiu cerca de $1,4 \mathrm{~m}$, conseqüência da resistência dos flocos às forças de cisalhamento, que possibilitou a sua penetração até as camadas mais profundas do meio filtrante. Durante os ensaios com pré-floculação observou-se intensa produção de flocos com tamanho estimado de 0,3 a $0,5 \mathrm{~mm}$.

A Figura 5 mostra a variação da perda de carga total no meio filtrante e na qualidade da água filtrada para dois ensaios da série C. Percebe-se uma ligeira melhora na qualidade da água filtrada em termos de turbidez, no ensaio com pré-floculação.

Embora o efeito maior da pré-floculação tenha sido prolongamento das carreiras de filtração pela redução da perda de carga, observou-se uma ligeira melhora na qualidade da água filtrada. Nos ensaios com a pré-floculação as concentraçōes de alumínio residual foram menores tendo o sulfato de alumínio como coagulante. Para os ensaios com hidróxicloreto de alumínio, a concentração de alumínio residual na água filtrada esteve abaixo do limite de detecção, independentemente da pré-floculação ou não, conforme mostra a Tabela 5 .

O consumo de água para lavagem dos filtros teve o seguinte comportamento médio: ensaios da série $\mathrm{A}=23,0 \%$; ensaios da série $\mathrm{B}=8,6 \%$; ensaios da série $C=9,3 \%$ - sem pré- floculação e 5,5\% - com pré-floculação. Portanto, a produção efetiva dos filtros, relação entre o volume produzido e o consumido na lavagem, variou de $76,8 \%$ a $94,8 \%$.

Para verificar se houve variação significativa na turbidez da água bruta durante os testes com e sem pré-floculação, já que os mesmos foram realizados em dias alternados, foi aplicado o teste de Mann-Whitney, aos dados da Tabela 5. Os resultados foram os seguintes:

Número de casos: n1 (com préfloculação) $=\mathrm{n} 2$ (sem pré-floculação) $=10$

Soma dos postos no grupo $\mathrm{n} 1$ : $\mathrm{R} 1=106$

Soma dos postos no grupo $\mathrm{n} 2$ : $\mathrm{R} 2=104$

Cálculo da estatística $\mu$ para o menor valor de R: R2 = 104

$\mu 2=\mathrm{n} 1 . \mathrm{n} 2+\frac{\mathrm{n} 2(\mathrm{n} 2+1)}{2}-\mathrm{R} 2=51$ 
Tabela 4 - Resultados de ensaios de filtração direta com e sem pré-floculação, janeiro-abril/2004

\begin{tabular}{|c|c|c|c|c|c|c|c|c|c|c|}
\hline \multirow[t]{2}{*}{ Ensaio } & \multicolumn{3}{|c|}{ Água bruta } & \multicolumn{2}{|c|}{ Coagulação } & \multicolumn{2}{|c|}{$\begin{array}{c}\text { Água filtrada } \\
\text { (sem pré-floculação) }\end{array}$} & \multicolumn{2}{|c|}{$\begin{array}{c}\text { Água filtrada } \\
\text { (com pré-floculação) }\end{array}$} & \multirow{2}{*}{$\begin{array}{c}\text { Duração } \\
\text { da } \\
\text { carreira } \\
\text { (h) }\end{array}$} \\
\hline & $\mathrm{pH}$ & $\begin{array}{l}\text { Turbidez } \\
\text { (uT) }\end{array}$ & $\begin{array}{c}\text { Cor } \\
\text { aparente } \\
(\mathrm{uH})\end{array}$ & $\mathrm{pH}$ & $\begin{array}{l}\text { Coagulante } \\
\mathrm{mg} / \mathrm{L} \text { (tipo) } \\
\mathrm{mg} / \mathrm{L} \mathrm{Al} \mathrm{Al}^{3+}\end{array}$ & $\begin{array}{l}\text { Turbidez } \\
\text { (uT) }\end{array}$ & $\begin{array}{c}\text { Cor } \\
\text { aparente } \\
(\mathrm{uH})\end{array}$ & $\begin{array}{l}\text { Turbidez } \\
\text { (uT) }\end{array}$ & $\begin{array}{c}\text { Cor } \\
\text { aparente } \\
(\mathrm{uH})\end{array}$ & \\
\hline $\mathrm{AC} 1$ & $\begin{array}{c}6,6 \\
6,4-6,8\end{array}$ & $\begin{array}{c}6,8 \\
6,13-7,61\end{array}$ & $\begin{array}{c}90,9 \\
85-97\end{array}$ & $\begin{array}{c}5,6 \\
5,5-5,7\end{array}$ & 16 (SA) 1,22 & - & - & $\begin{array}{c}0,6 \\
1,33-0,38\end{array}$ & $\begin{array}{c}7,4 \\
14-5\end{array}$ & 4,7 \\
\hline AS1 & $\begin{array}{c}6,8 \\
6,6-6,8\end{array}$ & $\begin{array}{c}7,2 \\
6,46-8,52\end{array}$ & $\begin{array}{c}94 \\
90-97\end{array}$ & $\begin{array}{c}5,7 \\
5,6-5,8\end{array}$ & $16(\mathrm{SA}) 1,22$ & $\begin{array}{c}0,6 \\
1,23-0,37\end{array}$ & $\begin{array}{c}6,7 \\
14-4\end{array}$ & - & - & 4,3 \\
\hline AC2 & $\begin{array}{c}6,8 \\
6,7-6,9\end{array}$ & $\begin{array}{c}7,3 \\
6,14-8,20\end{array}$ & $\begin{array}{c}91,9 \\
88-96\end{array}$ & $\begin{array}{c}5,7 \\
5,5-5,8\end{array}$ & 16 (SA) 1,22 & - & - & $\begin{array}{c}0,6 \\
1,25-0,43\end{array}$ & $\begin{array}{c}8,8 \\
17-5\end{array}$ & 5,8 \\
\hline AS2 & $\begin{array}{c}6,7 \\
6,4-6,9\end{array}$ & $\begin{array}{c}5,6 \\
4,83-6,54\end{array}$ & $\begin{array}{c}81,3 \\
72-90\end{array}$ & $\begin{array}{c}5,8 \\
5,7-5,8\end{array}$ & $16(\mathrm{SA}) 1,22$ & $\begin{array}{c}0,7 \\
1,52-0,46\end{array}$ & $\begin{array}{c}8,9 \\
17-6\end{array}$ & - & - & 6 \\
\hline AC3 & $\begin{array}{c}6,7 \\
6,5-6,9\end{array}$ & $\begin{array}{c}6,3 \\
5,19-7,26\end{array}$ & $\begin{array}{c}86 \\
81-88\end{array}$ & $\begin{array}{c}5,8 \\
5,6-6,0\end{array}$ & $18(\mathrm{SA}) 1,37$ & - & - & $\begin{array}{c}0,6 \\
1,13-0,39\end{array}$ & $\begin{array}{l}7,5 \\
16-4\end{array}$ & 5,5 \\
\hline AS3 & $\begin{array}{c}6,6 \\
6,45-6,8\end{array}$ & $\begin{array}{c}5,9 \\
5,17-6,61\end{array}$ & $\begin{array}{c}79,1 \\
76-81\end{array}$ & $\begin{array}{c}5,6 \\
5,5-5,8\end{array}$ & 18 (SA) 1,37 & $\begin{array}{c}0,6 \\
1,22-0,42\end{array}$ & $\begin{array}{c}7,3 \\
17-5\end{array}$ & - & - & 4,3 \\
\hline AC4 & $\begin{array}{c}6,6 \\
6,4-6,7\end{array}$ & $\begin{array}{c}6,8 \\
5,67-8,16\end{array}$ & $\begin{array}{c}85,1 \\
82-91\end{array}$ & $\begin{array}{c}5,8 \\
5,7-5,9\end{array}$ & 18 (SA) 1,37 & - & - & $\begin{array}{c}0,6 \\
1,34-0,41\end{array}$ & $\begin{array}{c}7 \\
14-5\end{array}$ & 4,7 \\
\hline AS4 & $\begin{array}{c}6,8 \\
6,8-6,9\end{array}$ & $\begin{array}{c}5,6 \\
5,35-5,8\end{array}$ & $\begin{array}{c}80,5 \\
79-82\end{array}$ & $\begin{array}{c}5,7 \\
5,65-5,8\end{array}$ & $18(\mathrm{SA}) 1,37$ & $\begin{array}{c}0,6 \\
1,12-0,38\end{array}$ & $\begin{array}{c}8 \\
16-4\end{array}$ & - & - & 5 \\
\hline $\mathrm{BC} 1$ & $\begin{array}{c}7 \\
6,96-7,36\end{array}$ & $\begin{array}{c}3,8 \\
3,15-4,35\end{array}$ & $\begin{array}{c}59,2 \\
54-62\end{array}$ & $\begin{array}{c}5,7 \\
5,4-5,82\end{array}$ & $24(\mathrm{SA}) 1,82$ & - & - & $\begin{array}{c}0,5 \\
1,21-0,35\end{array}$ & $\begin{array}{c}7 \\
14-5\end{array}$ & 11,8 \\
\hline BS1 & $\begin{array}{c}7 \\
6,5-7,4\end{array}$ & $\begin{array}{c}3,6 \\
3,17-4,14\end{array}$ & $\begin{array}{c}58,1 \\
52-63\end{array}$ & $\begin{array}{c}5,7 \\
5,4-5,9\end{array}$ & $\begin{array}{c}23(\mathrm{SA}) 1,75 \\
22-24\end{array}$ & $\begin{array}{c}0,6 \\
1,74-0,38\end{array}$ & $\begin{array}{c}7,1 \\
24-5\end{array}$ & - & - & 12,5 \\
\hline $\mathrm{BC} 2$ & $\begin{array}{c}7 \\
6,87-8,38\end{array}$ & $\begin{array}{c}4 \\
3,47-4,56\end{array}$ & $\begin{array}{c}55,5 \\
53-58\end{array}$ & $\begin{array}{c}5,9 \\
5,75-6,34\end{array}$ & $\begin{array}{c}28(\mathrm{SA}) 2,13 \\
27-29\end{array}$ & - & - & $\begin{array}{c}0,5 \\
1,53-0,29\end{array}$ & $\begin{array}{c}5,5 \\
23-3\end{array}$ & 15,5 \\
\hline BS2 & $\begin{array}{c}7 \\
6,84-7,47\end{array}$ & $\begin{array}{c}3,9 \\
3,28-4,97\end{array}$ & $\begin{array}{c}53,9 \\
48-59\end{array}$ & $\begin{array}{c}5,8 \\
5,75-5,92\end{array}$ & $\begin{array}{c}27(\mathrm{SA}) 2,05 \\
24-28\end{array}$ & $\begin{array}{c}0,5 \\
1,21-0,35\end{array}$ & $\begin{array}{c}6,1 \\
14-4\end{array}$ & - & - & 14 \\
\hline BC3 & $\begin{array}{c}7 \\
6,87-7,08\end{array}$ & $\begin{array}{c}4 \\
3,47-4,54\end{array}$ & $\begin{array}{c}62,3 \\
59-65\end{array}$ & $\begin{array}{c}5,8 \\
5,71-5,91\end{array}$ & $\begin{array}{c}28,8(\mathrm{SA}) 2,2 \\
28-29\end{array}$ & - & - & $\begin{array}{c}0,5 \\
1,53-0,33\end{array}$ & $\begin{array}{c}5,9 \\
25-3\end{array}$ & 13 \\
\hline BS3 & $\begin{array}{c}7 \\
6,9-7,08\end{array}$ & $\begin{array}{c}4 \\
3,83-4,09\end{array}$ & $\begin{array}{c}56,8 \\
52-59\end{array}$ & $\begin{array}{c}5,8 \\
5,76-5,84\end{array}$ & $28(\mathrm{SA}) 2,13$ & $\begin{array}{c}0,5 \\
1,51-0,38\end{array}$ & $\begin{array}{c}6,3 \\
17-5\end{array}$ & - & - & 13,5 \\
\hline $\mathrm{CC} 1$ & $\begin{array}{c}7,5 \\
6,35-8,94\end{array}$ & $\begin{array}{c}3,5 \\
3,13-4,55\end{array}$ & $\begin{array}{c}53,9 \\
50-58\end{array}$ & $\begin{array}{c}6 \\
5,79-6,29\end{array}$ & 22 (PAC) 1,1 & - & - & $\begin{array}{c}0,6 \\
0,91-0,34\end{array}$ & $\begin{array}{c}7,5 \\
13-5\end{array}$ & $\begin{array}{l}21,5 \\
* 17\end{array}$ \\
\hline CS1 & $\begin{array}{c}6,9 \\
6,57-8,48\end{array}$ & $\begin{array}{c}3,6 \\
3,24-4,03\end{array}$ & $\begin{array}{c}57,3 \\
53-64\end{array}$ & $\begin{array}{c}6,1 \\
5,95-6,24\end{array}$ & 22 (PAC) 1,1 & $\begin{array}{c}0,4 \\
0,72-0,28\end{array}$ & $\begin{array}{c}5,6 \\
11-2\end{array}$ & - & - & 13,3 \\
\hline CC2 & $\begin{array}{c}7,1 \\
6,37-8,61\end{array}$ & $\begin{array}{c}4 \\
3,51-4,86\end{array}$ & $\begin{array}{c}60,7 \\
57-66\end{array}$ & $\begin{array}{c}5,9 \\
5,79-6,22\end{array}$ & $22(\mathrm{PAC}) 1,1$ & - & - & $\begin{array}{c}0,4 \\
0,97-0,25\end{array}$ & $\begin{array}{c}5,8 \\
14-3\end{array}$ & 20,7 \\
\hline CS2 & $\begin{array}{c}6,8 \\
5,98-7,84\end{array}$ & $\begin{array}{c}4,2 \\
3,47-4,75\end{array}$ & $\begin{array}{c}65,4 \\
60-71\end{array}$ & $\begin{array}{c}6 \\
5,7-6,3\end{array}$ & $\begin{array}{c}21(\mathrm{PAC}) 1,05 \\
20-22\end{array}$ & $\begin{array}{c}0,5 \\
0,57-0,39\end{array}$ & $\begin{array}{c}7,4 \\
10-5\end{array}$ & - & - & 12,4 \\
\hline CC3 & $\begin{array}{c}7,1 \\
6,53-8,9\end{array}$ & $\begin{array}{c}3,5 \\
3,01-3,98\end{array}$ & $\begin{array}{c}49 \\
44-61\end{array}$ & $\begin{array}{c}6 \\
5,76-6,15\end{array}$ & 22 (PAC) 1,1 & - & - & $\begin{array}{c}0,4 \\
0,69-0,3\end{array}$ & $\begin{array}{l}4,9 \\
9-2\end{array}$ & 22,4 \\
\hline CS3 & $\begin{array}{c}6,6 \\
6,08-6,86\end{array}$ & $\begin{array}{c}3,8 \\
3,1-4,73\end{array}$ & $\begin{array}{c}50,5 \\
43-56\end{array}$ & $\begin{array}{c}6 \\
5,91-6,08\end{array}$ & $\begin{array}{c}21(\mathrm{PAC}) 1,05 \\
20-22\end{array}$ & $\begin{array}{c}0,5 \\
0,53-0,39\end{array}$ & $\begin{array}{l}5,1 \\
6-3\end{array}$ & - & - & 13 \\
\hline
\end{tabular}

OBS: Os valores separados por hífen (Ex: 43-56) representam a faixa de variação do parâmetro.
* Carreira encerrada com duração de 17:00 h e 1,31m de perda de carga, devido fortes variações no pH da água bruta, dificultando o controle do pH de coagulaçáo e consequentemente da qualidade da água filtrada. $21,5 \mathrm{~h}$ representa a duraçáo estimada da carreira para atingir $1,76 \mathrm{~m}$ de perda de carga. Exemplo: AS2 = ensaio 2 da série A Sem pré-floculação; AC2 = ensaio 2 da série A Com pré-floculação. 
Testar no nível de 5\% as hipóteses.

$\mathrm{H}_{0}=$ Não há diferença entre os valores médios de turbidez.

$\mathrm{H}_{1}=$ Há diferença entre os valores médios de turbidez.

Para $\alpha=5 \%$ na tabela de xdistribuição normal (Fonseca,1996) obteve-se: $Z \alpha / 2 \cong 1,91$.Determinação da variável $Z_{\mathrm{cal}}$

$\mu(\mathrm{u})=\frac{\mathrm{n} 1 \cdot \mathrm{n} 2}{2}=50$

$\sigma(u)=\sqrt{\frac{n 1 \cdot n 2(n 1+n 2+n 1)}{12}}=13,23$

$\mathrm{Z}_{\mathrm{cal}}=\frac{\mu-\mu(\mathrm{u})}{\sigma(\mathrm{u})}=0,075$

Como $-1,91<0,075<1,91$, não se pode rejeitar $\mathrm{H}_{0}$. Conclui-se que existe um risco menor que $5 \%$ de haver diferença entre os valores médios na turbidez da água bruta, dos ensaios com e sem pré-floculação.

\section{CONCLUSÕES}

A filtração direta descendente não deve ser a escolha para tratamento de águas com presença de fitoplâncton em número e espécies indicadas nesse trabalho. Entretanto em sistemas implantados, é possível otimizar a tecnologia para obter condições razoáveis em termos de produção e qualidade da água;

A pré-floculação mostrou benefícios em termos de aumento na duração das carreiras de filtração, entretanto o sucesso de sua aplicação depende do coagulante utilizado e das características do meio filtrante. No presente estudo o hidróxicloreto de alumínio forneceu os melhores resultados, enquanto com sulfato de alumínio não houve benefícios em termos de aumento na duração das carreiras de filtração;

A qualidade da água filtrada em termos de cor aparente e turbidez foi levemente beneficiada pela pré-floculação, principalmente com a utilização do hidroxicloreto de alumínio. Os níveis de alumínio residual na água filtrada foram em média $41 \%$ menores com a pré-floculação utilizando sulfato de alumínio, e não detectáveis pelo método analítico empregado, utilizando-se hidroxicloreto de alumínio com ou sem pré-floculação;

A pré-floculação com sulfato de alumínio, contribuiu para manutenção com maior facilidade, dos níveis de

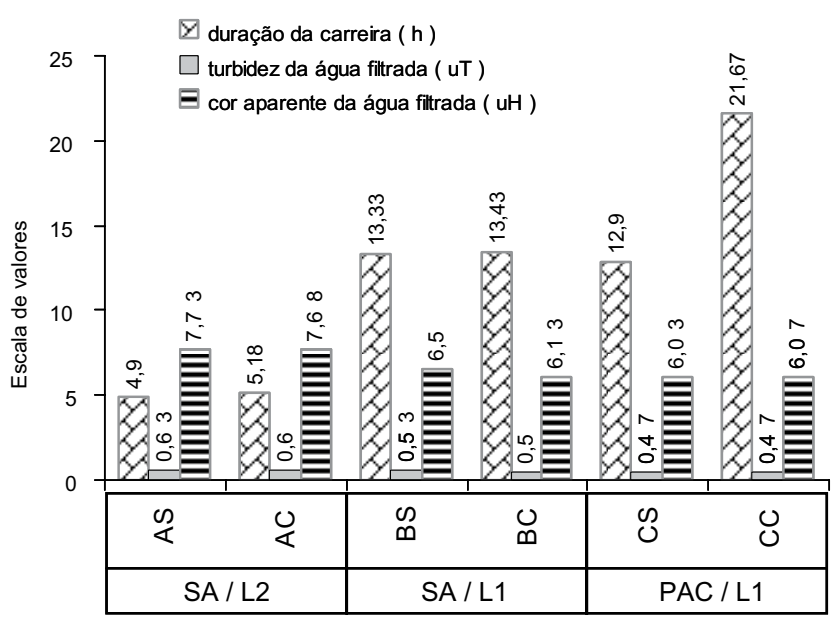

Ensaios de filtração direta

\section{Figura 3 - Valores médios de qualidade da água filtrada} e duração das carreiras
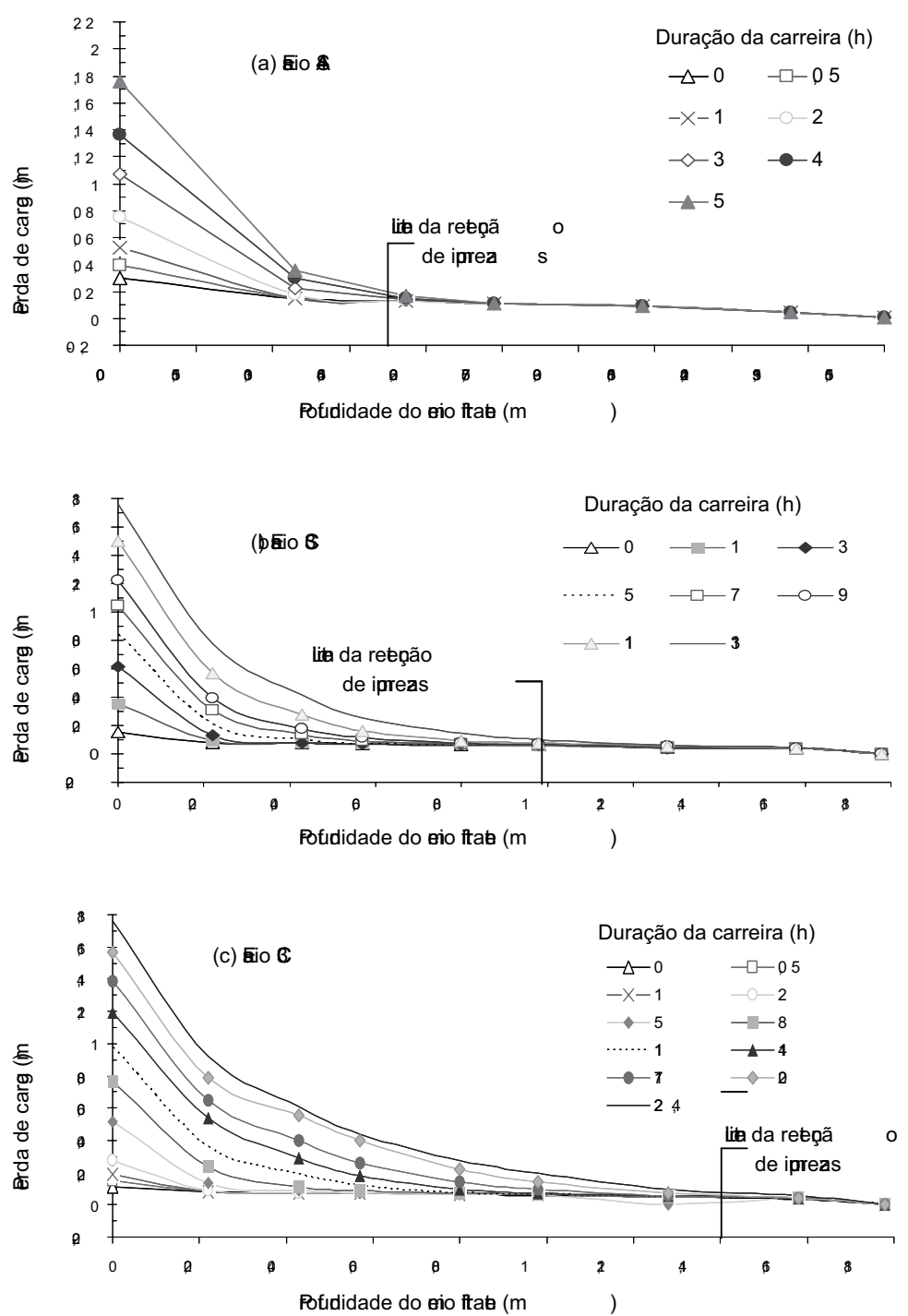

Figura 4 - Comparativo da variação da perda de carga no meio filtrante nos ensaios de filtração direta, em função do tipo de leito e do coagulante 
Tabela 5 - Alumínio residual nos ensaios de filtração direta com e sem pré-floculação

\begin{tabular}{|c|c|c|c|c|c|}
\hline Ensaio & $\begin{array}{l}\text { Alumínio } \\
\text { Residual } \\
\mathrm{mg} / \mathrm{L} \mathrm{Al}^{3+}\end{array}$ & Ensaio & $\begin{array}{c}\text { Alumínio } \\
\text { Residual } \\
\mathrm{mg} / \mathrm{L} \mathrm{Al}^{3+}\end{array}$ & Ensaio & $\begin{array}{c}\text { Alumínio } \\
\text { Residual } \\
\mathrm{mg} / \mathrm{L} \mathrm{Al}^{3+}\end{array}$ \\
\hline $\mathrm{AC} 1$ & 0,17 & AS4 & 0,24 & CS1 & $<0,01$ \\
\hline AS 1 & 0,23 & BC1 & 0,15 & $\mathrm{CC} 1$ & $<0,01$ \\
\hline $\mathrm{AC} 2$ & 0,15 & BS1 & 0,32 & CS2 & $<0,01$ \\
\hline AS2 & 0,25 & BC2 & 0,10 & CC2 & $<0,01$ \\
\hline AC3 & 0,15 & BS2 & 0,19 & CS3 & $<0,01$ \\
\hline AS3 & 0,19 & BC3 & 0,09 & $\mathrm{CC} 3$ & $<0,01$ \\
\hline AC4 & 0,09 & BS3 & 0,12 & & \\
\hline
\end{tabular}

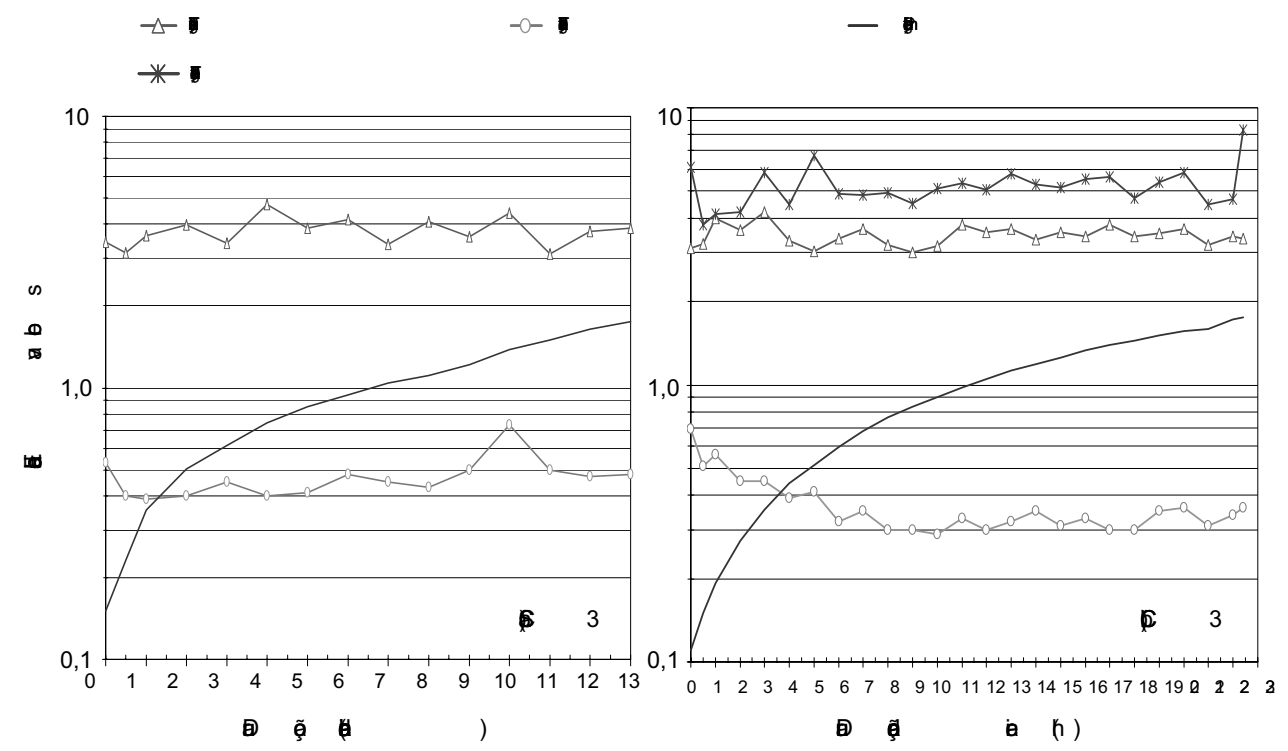

Figura 5 - Variações na perda de carga e na qualidade da água filtrada entre ensaios de filtração direta descendente com e sem pré-floculação

qualidade da água filtrada em termos de cor aparente e turbidez, frente às variações no $\mathrm{pH}$ de coagulação decorrentes das variações no $\mathrm{pH}$ da água bruta, considerando o controle operacional do sistema piloto.

\section{REFERÊNCIAS}

ARBOLEDA, J.V. Teoria y práctica de la purificación del agua-TOMO 2. Editora McGraw-Hill. Santa Fe de Bogotá. Colombia: 2000.

BRANDĀO, C.C.S,; LACERDA, M.R.S.; ABREU, M. C. Influência do tempo de floculação na filtração direta de águas com baixa turbidez e teor elevado de algas. In: VII SIMPÓSIO LUSO-BRASILEIRO DE ENGENHARIA SANITÁRIA E AMBIENTAL, Anais...Lisboa, Portugal, 1996.

DALSASSO, R. L. et al. Floculação em meio granular com materiais alternativos. In: $22^{\circ} \mathrm{CON}$ GRESSO BRASILEIRO DE ENGENHARIA SANITÁRIA E AMBIENTAL, Joinvile, SC. ABES, 2003.
DE PÁDUA, V. L. Filtração Direta Descendente - Investigação experimental da coagulação, floculação e filtração em instalação piloto. Relatório de atividades - PROSAB 3. Universidade Federal do Ceará, 2001.

DI BERNARDO, L. et al. Tratamento de Água para Abastecimento por Filtração Direta. PROSAB 3. RIMA Editora, 498p. Rio de Janeiro, 2003.

FONSECA, J.S.; MARTINS, G. A. Curso de Estatistica. Editora Atlas S.A., 320p. São Paulo, 1996.

RISSOLI, M. C., CARVALHO, R.P.M., BRANDÃO, C.C.S. O efeito da coagulação quimica na pré-filtração em pedregulho de águas com presença de algas, e seu potencial como pré-tratamento para a filtração rápida descendente. In: XXVII CONGRESSO INTERAMERICANO DE ENGENHARIA SANITÁRIA E AMBIENTAL, Anais.. Porto Alegre - Brasil, pp 1-11. 2000.

SILVA, R. L. Aspectos limnológicos, variabilidade espacial e temporal na estrutura da comunidade fitoplanctônica da Lagoa do Peri. Santa Catarina, Brasil. Tese de doutorado. 218 p. São Carlos, UFSCar, 1999.
Endereço para correspondência:

Ramon Lucas Dalsasso

Departamento de Engenharia

Sanitária e Ambiental

Universidade Federal de Santa

Catarina

Centro Tecnológico

Campus Universitário

Caixa Postal $n^{\circ} 476$

88040-070 Trindade -

Florianópolis - SC - Brasil

Tel.: (48)333 I-9470

E-mail:dalsasso@ens.ufsc.br 